\title{
Combined effect of cadmium and noise on rat's kidney
}

\author{
Ameneh Golbaghi $^{\circledR}$, Behzad Fouladi Dehagi ${ }^{1}{ }^{\circledR}$, Massumeh Ahmadizadeh ${ }^{1,2^{*}}(\mathbb{0}$ \\ ${ }^{1}$ Department of Occupational Health Engineering, School of Health, Ahvaz Jundishapur University of Medical Sciences, Ahvaz, Iran \\ ${ }^{2}$ Physiology Research Center, Ahvaz Jundishapur University of Medical Sciences, Ahvaz, Iran
}

\section{A R T I C L E I N F O}

\section{Article Type:}

Original

\section{Article History:}

Received: 6 September 2018

Accepted: 20 January 2019

Published online: 28 February 2019

\section{Keywords:}

Cadmium chloride

Noise

Renal function

Oxidative stress

Nephrotoxicity

\begin{abstract}
A B S T RAC T
Introduction: Recently, the consequence of chemical industries and noise on human health is the update subject for researchers. There are many reports published about nephrotoxicity of noise and cadmium alone.

Objectives: The main aim of this study was to detect the combined consequence of noise and cadmium on renal function.

Materials and Methods: Forty adult male rats were put into eight groups in random order $(\mathrm{n}=5)$. Groups 1 control, group 2 exposed to $90 \mathrm{~dB}$ (decibels) noise, groups 3- 5 received (intraperitoneal; ip) cadmium chloride $(\mathrm{CdCl} 2)$ at doses of $1,2,3 \mathrm{mg} / \mathrm{kg}$ and group $6-8$ pretreated with $\mathrm{CdCl} 2$ at doses of 1,2 , and $3 \mathrm{mg} / \mathrm{kg} 30$ minutes before exposing to $90 \mathrm{~dB}$ noise. The exercise was repeated for seven consecutive days. Animals were killed 24 hours afterwards. Blood urea nitrogen $(\mathrm{BUN})$ and creatinine $(\mathrm{Cr})$ levels were analyzed. Kidney tissues were excised for measuring malondialdehyde (MDA) and glutathione (GSH) concentrations.

Results: There was significant rise on the levels of BUN, Cr and MDA. Additionally, a decrease on the level of GSH in rats that were exposed to noise or cadmium alone or combined to noise and cadmium was detected. Significant elevation of BUN, Cr, MDA and depletion of GSH were also noted in cadmium-treated rats compared to those in the animals co-exposed to cadmium and noise.

Conclusion: This study shows that exposed rats to cadmium and/or noise caused renal function impairment. Production of oxidative stress is responsible for cadmium or noise induced nephrotoxicity. However, co-exposure of cadmium and noise reduced nephrotoxicity of cadmium. The possible explanation for noises suppressing cadmium nephrotoxicity is that noise may enhance excretion and/or induced redistribution and depleted accumulation of cadmium in the kidney.
\end{abstract}

Implication for health policy/practice/research/medical education:

Current investigation represented interaction of cadmium and noise-induced toxicity in rat's kidney. This investigation was asserted an exposure to either cadmium or noise is known to compromise human health. Both agents induced renal function impairment and produced oxidative stress. However, noise caused suppression of cadmium nephrotoxicity. The mechanism by which noise decreased cadmium nephrotoxicity may be due to noise enhances cadmium excretion and/or noise-induced redistribution and gathering of cadmium in other regions of the body.

Please cite this paper as: Golbaghi A, Fouladi Dehagi B, Ahmadizadeh M. Combined effect of cadmium and noise on rat's kidney. J Renal Inj Prev. 2019;8(3):230-234. DOI: 10.15171/jrip.2019.43.

\section{Introduction}

One of the heavy metals that found in abundance in nature is cadmium with a widespread environmental pollutant. It has been known that it can cause adverse effects in many vital organs including the liver, lung, bone, kidney, testis, placenta and auditory system (1). The kidney is one of the main target organ for cadmium toxicity (1-4). Increasing evidence support the view that production of reactive oxygen species is the most known cause of cadmium toxicity (3-6).
Noise is defined as unwanted sound. Hearing loss, cardiovascular disease, sleep disturbance and kidney function impairment are the main health problems associated with noise exposure (1,7-9). Zaghloul et al reported biochemical alteration of rat kidney following one week of noise exposure (8). Although evidence supports that oxidative stress is the main reason for noise produced adverse effects, the cause of which noise influenced adverse effects is not completely understood. Recently several investigations have exercised the 
influence of combined exposure to noise and chemical substances. The impact of noise and organic solvent on non-auditory system was reported by several investigators (10-13). Exposure to noise and xylene induced biochemical alterations in rat heart muscle (10). Ivanovich et al showed a combined effect of dimethylformamide and noise caused changes in rat metabolism of heart. However, these authors find an independent effect of two factors (10). Heavy metals such as arsenic, mercury, cadmium and lead are present in many forms in the environment and are widely present in number of industrial sectors. It has been reported that combined exposure of noise and lead induced oxidative stress in rat serum (13).

Additionally, Conetta et al found that the co-exposure of noise and cadmium produced histological damage in rat heart muscle (7). The mechanism of noise-induced injury is known to be increased oxidative stress (14). Cadmium is also known to cause kidney damage by producing oxidative stress (15).

\section{Objectives}

However, as general information, the combined influence of cadmium and noise is not reported in the kidney. The aim of current study was to evaluate the effect of combined noise and cadmium in the kidney by using rats as an experimental animal model.

\section{Materials and Methods}

\section{Chemicals}

Cadmium chloride $\left(\mathrm{CdCl}_{2}\right)$, ethanol, $\mathrm{NaCl}$ and EDTA were prepared from Merck chemical company. Thiobarbituric acid (TBA), trichloroacetic acid (TCA), 5, 5-dithiobis (2-nitrobanzoic acid) (DTNB) were prepared from Sigma Co. (USA). Urea and creatinine (Cr) kits were purchased from Azmoun Pars Company.

\section{Animals and experimental groups}

Adult male albino Wistar rats with 200-250 g body weight were prepared from maintenance center of laboratory animals of Ahvaz Jundishapur University of Medical Sciences for the current study. They were managed to divide into eight random groups and stay under 12/12hour brightness/ darkness conditions at a temperature of $23 \pm 2{ }^{\circ} \mathrm{C}$ with free access to water and food. Eight groups (each 5), as follows:

Group 1: control group (without administration cadmium chloride and without exposed to noise). The animals have been regulated in the chamber under an same conditions as that of the experimental groups except for the noise exposure.

Group 2: Exposed to noise $90 \mathrm{~dB}$ (decibels) 4 hours daily for 1 week (without administration cadmium chloride).

Groups 3 to 5: received $\mathrm{CdCl}_{2}$ ( $1 \mathrm{mg} / \mathrm{kg}, 2 \mathrm{mg} / \mathrm{kg}, 3 \mathrm{mg} /$ $\mathrm{kg}$ ) respectively for 7 consecutive days without exposure to noise. Groups 6 to 8 received $\mathrm{CdCl}_{2}(1 \mathrm{mg} / \mathrm{kg}, 2 \mathrm{mg} / \mathrm{kg}$,
$3 \mathrm{mg} / \mathrm{kg}$ ) respectively 30 minutes prior exposed to noise (90 dB, 4 hours daily for 1 week).

All rats were killed 24 hours after the last experiment, with an overdose of sodium pentobarbital. Blood samples were used for assessment of blood urea nitrogen (BUN) and $\mathrm{Cr}$. The methods of diacetyl monoxide and Jaffe were used for the evaluation of BUN and $\mathrm{Cr}$, respectively $(16,17)$.

The kidney was dissected out, weighed and washed with the use of chilled saline solution. Homogenized and minced tissue was examined $(10 \% \mathrm{w} / \mathrm{v})$ in phosphate buffer ( $\mathrm{pH} 7.4)$ and centrifuged ( $3000 \times \mathrm{g}$ for 10 minutes). Biochemical assays will use the resulting supernatant.

Glutathione (GSH) and malondialdehyde (MDA) concentrations were determined according to the methods of Ellman (18) and Buege and Aust (19).

\section{Noise exposure}

Broadband (White) noise $90 \mathrm{~dB}(\mathrm{~A})$ an octave. The intensity of the sound was examined by a sound level meter (CEL-450). Animals were exposed to white noise [4 $\mathrm{h} / \mathrm{d}$ under $90 \mathrm{~dB}$, (A for one week)] at 09:00 AM to 13:00 PM. The level of $90 \mathrm{~dB}$ (A) was picked, as it is similar to the level of noise is detected in some industrial workplaces $(20,21)$.

\section{Ethical issues}

This study was confirmed by Ethics Committee of Ahvaz Jundishapur University of Medical Sciences. As an experiment, the protocols were approved to be in accordance with the guidelines of Animal Ethics Committee of Ahvaz Jundishapur University of Medical Sciences (IR.AJUMS.REC.1396.674). This practice was supported by Physiology Research Center and the research deputy of Ahvaz Jundishapur University of Medical Sciences (Grant \#APRC-9613).

\section{Statistical analysis}

Data were tested for homogeneity of variance. Analysis of variance (ANOVA) was applied to determine the significant differences between data groups. For the comparison of means in order to determine significant differences $(P \leq 0.05)$, the Tukey's test was used. All statistical analysis was performed using SPSS version 17 software.

\section{Results}

\section{Renal function tests}

A dose-dependent increased the level of BUN in rats exposed to cadmium chloride, noise and co-exposed to cadmium and noise once liken to those in control animals. Serum BUN was also significantly increased $(P \leq 0.05)$ in the animals examined under various doses of cadmium chloride in comparison to the animals co-exposed to cadmium chloride and noise (Figure 1). Exposure of rats 
to cadmium chloride, noise and combined to cadmium chloride and noise significantly $(P \leq 0.05)$ elevated the level of serum $\mathrm{Cr}$ once in comparison to those in unexposed control rats (Figure 2). Serum $\mathrm{Cr}$ was also markedly $(P \leq 0.05)$ increased in rats treated with various doses of cadmium chloride in comparison to the animals co-exposed to cadmium chloride and noise (Figure 2).

\section{Kidney oxidative stress evaluation}

Kidney MDA level significantly increased in rats exposed to cadmium chloride, noise and combined cadmium chloride in comparison to those in control unexposed rats (Figure 3). The level of MDA also increased in rats exercised under various doses of cadmium chloride in comparison to the animals co-exposed to cadmium chloride and noise and it was a significant difference in the rats examined with $1 \mathrm{mg} / \mathrm{kg}$ cadmium chloride in comparison to those received the same dose of cadmium chloride and exposed to noise (Figure 3).

Exposure of rats to noise, cadmium chloride and combined cadmium chloride showed a significant decrease in kidney GSH level compared to unexposed control rats $(P \leq 0.05)$. Kidney GSH level was also markedly decreased in the animals treated with cadmium chloride compared to those exposed to combined cadmium chloride and

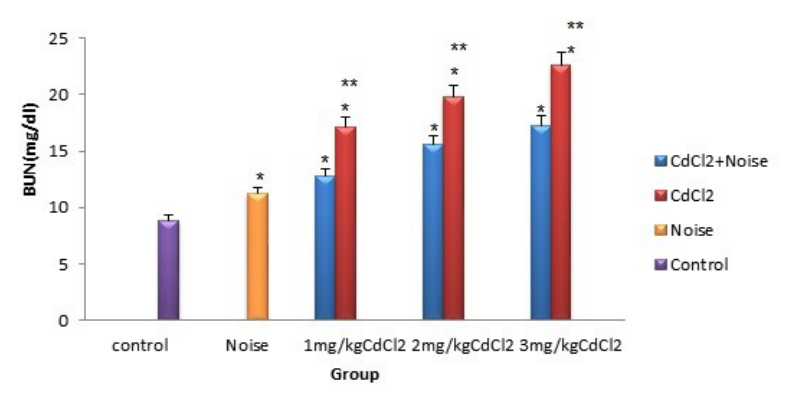

Figure 1. Effects of noise, cadmium $(\mathrm{CdCl} 2)$ and co-exposure of cadmium and noise on BUN in rats. ${ }^{*}$ Significant difference from control rats $(P \leq$ $0.05)$. ** Significant difference from animals exposed to the same dose of $\mathrm{CdCl}_{2}$ and exposed to noise $(P \leq 0.05)$

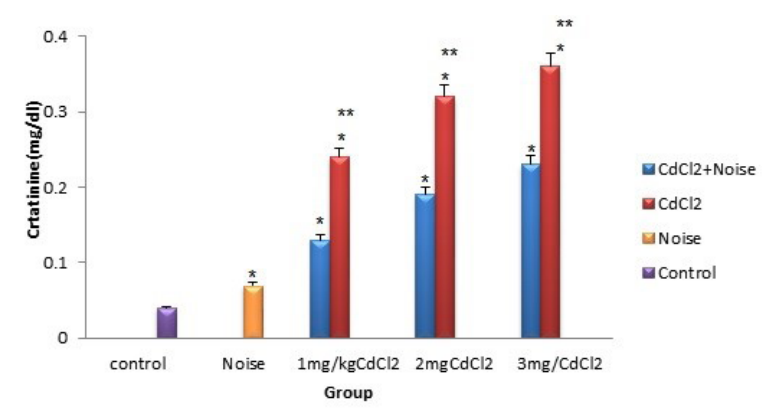

Figure 2. Effects of noise, cadmium $\left(\mathrm{CdCl}_{2}\right)$ and co-exposure of cadmium and noise on creatinine in rat. ${ }^{*}$ Significant difference from control rats $(P$ $\leq 0.05)$. ${ }^{*}$ Significant difference from animals exposed to the same dose of $\mathrm{CdCl} 2$ and exposed to noise $(P \leq 0.05)$. noise (Figure 4).

\section{Discussion}

Studies on kidney have been generated considerable interest that due to its role as a target organ for many toxic chemicals. In the present study, cadmium administration produced dose-dependent increased in renal function biomarkers including BUN and $\mathrm{Cr}$ and induced oxidative stress as shown by increase of MDA and decrease of GSH levels in rat's kidney. Our results revealed that cadmiuminduced nephrotoxicity is related to the generation of oxidative stress in the kidney. Akinyemi et al reported that cadmium produced renal injury in rat and ginger with antioxidant property protect kidney against cadmium nephrotoxicity (22). Abdel-Moneim and Said observed cadmium produced a significant decreased the antioxidant enzymes activity in kidney tissue which might be the effect of the overproduction of reactive oxygen species (ROS) (23). Evidence supports that production of oxidative stress is the most responsible reason for cadmium toxicity (22-26).

The impact of noise exposure on non-auditory system and public health has attracted many researchers. We found levels of BUN, Cr and MDA significantly increased and GSH concentration significantly dropped in rats

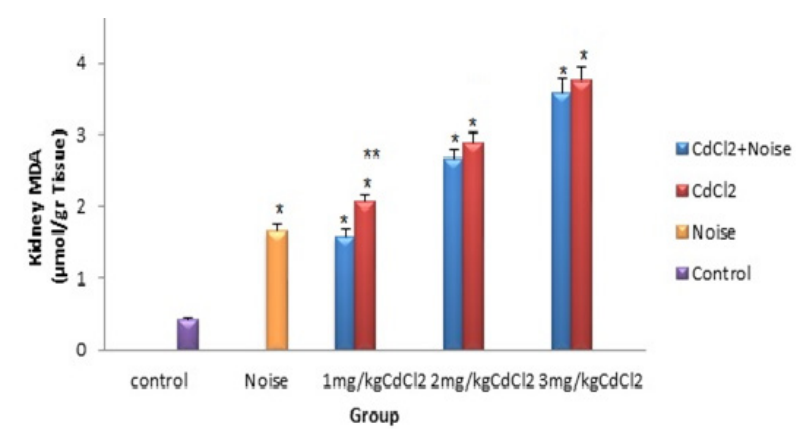

Figure 3. Effects of noise, cadmium $\left(\mathrm{CdCl}_{2}\right)$ and co-exposure of cadmium and noise on rat's kidney malondialdehyde (MDA). *Significant difference from control rats $(P \leq 0.05)$. ${ }^{* *}$ Significant difference from animals exposed to the same dose of $\mathrm{CdCl}_{2}$ and exposed to noise $(P \leq 0.05)$.

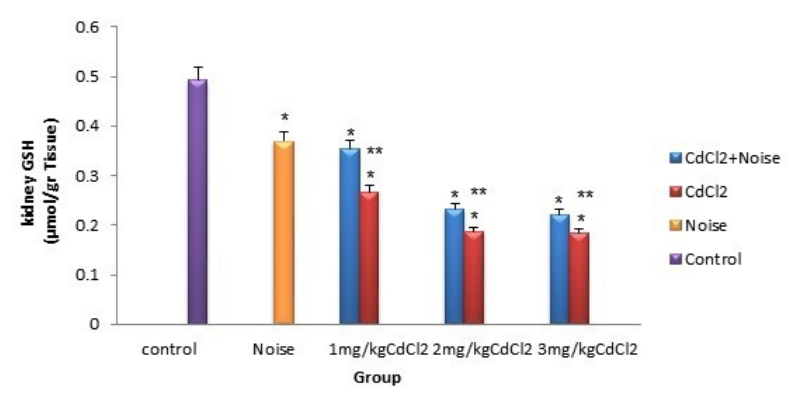

Figure 4. Effects of noise, cadmium ( $\mathrm{CdCl} 2)$ and co-exposure of cadmium and noise on rat's kidney glutathione (GSH). *Significant difference from control rats $(P \leq 0.05)$. ${ }^{* *}$ Significant difference from animals exposed to the same dose of $\mathrm{CdCl}_{2}$ and exposed to noise $(P \leq 0.05)$. 
exposed to noise in comparison to those in control, unexposed rats. This observation is consistent with others studies $(8,20,27,28)$ and supports the view that noise has potential to produce harmful effects in rat kidney.

The studies which have emphasized the potential effect of noise and industrial chemicals on non-auditory tissues are very limited. The present study examines the possibility that cadmium and noise have serious interaction. We found combined exposure to noise and cadmium impaired renal function as determined by increasing BUN and $\mathrm{Cr}$ levels in comparison to those in control rats. However, noise-induced suppression of cadmium nephrotoxicity as estimated by impaired renal function and produced oxidative stress. The mechanism by which noise alters cadmium caused renal damage may due to noise enhanced excretion and/or redistribute and accumulate of cadmium in other organs. Therefore, due to a reduced interaction between cadmium and target kidney cells, nephrotoxicity of cadmium diminished

$\mathrm{Pal}$ et al suggested once cadmium is co-exposed with ethanol, a significant increase in the accumulation of cadmium in different zones of rat brain will ensue. These authors suggested that ethanol may redistribute cadmium in rat's brain (29). Kershaw et al reported ethanol decreased hepatotoxicity of cadmium in rats (30).

Prasher et al reported the combined effect of noise and cadmium illustrated no synergistic effect on the teratogenicity in rat (1). Masruri et al found the exposure to noise and combined noise and lead induced oxidative stress in rats in comparison to those in control animals. However no significant differences in lipid peroxidation level between rats exposed to noise and combined noise and lead were noted (13).

\section{Conclusion}

Exposure rats to cadmium, noise and combined cadmium and noise produced renal function impairment and induced oxidative stress when compared to those in control rats. Nevertheless, co-exposure of cadmium and noise produce less nephrotoxicity when compared to those animals exposed to cadmium alone. The possible mechanism of this interaction is that noise accelerate excretion of cadmium and/or the noise makes redistribute and accumulation of the cadmium in other organs. Therefore interaction of cadmium with the receptor of target cell decreased and reduced nephrotoxicity.

\section{Acknowledgments}

The authors wish to thank the research deputy of Ahvaz Jundishapur University of Medical Sciences for offering the grants for this investigation. The source of data used in this paper was from the master thesis of Ameneh Golbaghi, the student of Occupational Health Engineering Department, School of Health, Ahvaz Jundishapur University of Medical Sciences, Ahvaz, Iran

\section{Authors' contribution}

AG provided technical assistance, collection and preparation of the manuscript. BF acted as a consultan. MA designed, supervised the study and prepared the final draft of the article.

\section{Conflicts of interest}

The authors declare no conflict of interest.

\section{Ethical considerations}

Ethical issues (including plagiarism, data fabrication, double publication) have been completely observed by the authors.

\section{Funding/Support}

This study was supported by Physiology Research Center and the research deputy of Ahvaz Jundishapur University of Medical Sciences (Grant \#APRC-9613).

\section{References}

1. Prasher D. Heavy metals and noise exposure.Health effects. Noise Health. 2009;11:141-4. doi: 10.4103/1463-1741.53358

2. Kim KS, Lim HJ, Lim JS, Son JY, Lee J, Lee BM, Chang SC, Kim HS. Curcumin ameliorates cadmium-induced nephrotoxicity in Sprague-Dawley rats. Food Chem Toxicol. 2018;114:34-40. doi: 10.1016/j.fct.2018.02.007

3. Elkhadragy MF, Al-Olayan EM, Al-Amiery AA, Abdel Moneim AE. Protective effects of fragaria ananassa extract against cadmium chloride-induced acute renal toxicity in rats. Biol Trace Elem Res. 2018; 181:378-87. doi: 10.1007/ s12011-017-1062-7.

4. Luo T, Liu G, Long M, Yang J, Song R, Wang Y, et al. Treatment of cadmium-induced renal oxidative damage in rats by administration of alpha-lipoic acid. Environ Sci Pollut Res Int. 2017;24:1832-1844.

5. Ansari MA, Raish M, Ahmad A, Alkharfy KM, Ahmad SF, Attia SM, et al. Sinapic acid ameliorate cadmiuminduced nephrotoxicity: In vivo possible involvement of oxidative stress, apoptosis, and inflammation via NF- $\mathrm{KB}$ downregulation. Environ Toxicol Pharmacol. 2017;51:100107. doi: 10.1016/j.etap.2017.02.014

6. Luo T, Liu G, Long M, Yang J, Song R, Wang Y, et al. Treatment of cadmium-induced renal oxidative damage in rats by administration of alpha-lipoic acid. Environ Sci Pollut Res Int. 2017;24:1832-44.

7. Conetta, J. Histologic effects of noise in the hearts of laboratory rats exposed to lead and cadmium. J Environ Sci Health. 1993;A28:403-421.

8. Zaghloul MS. Histological, histochemical and biochemical studies of the effect of chronic exposure of noise stress on the kidney of albino rats. J Am Sci. 2011;7(8):588-98.

9. Basner M, Babisch W, Davis A, Brink M, Clark C, Janssen $\mathrm{S}$, et al. Auditory and non-auditory effects of noise on health. Lancet. 2014;383:1325-32. doi: 10.1016/S01406736(13)61613-X

10. Ivanovich E, Antov G, Goranova L, Spasovski M, Bainova A, Vasileva Z. Combined effect of some physical and chemical factors. J Hyg Epidemiol Microbiol Immunol. 1985;29:105-10. 
11. Tehrani M, Khavanin A, Asilian H. Effects of simultaneous exposure to noise and styrene on rat liver enzymes. J Occup Health Epid . 2016;5:245-52.

12. Attarchi M, Golabadi M, Labbafinejad Y, Mohammadi S. Combined effects of exposure to occupational noise and mixed organic solvents on blood pressure in car manufacturing company workers. Am J Ind Med. 2013;56(2):243-51. doi: 10.1002/ajim.22086.

13. Masruri B, Ashtarinezhad A, Yekzamani P. Data on the effect of lead concomitant noise on oxidative stress in rats. Data Brief. 2018;18:1117-21. doi: 10.1016/j.dib.2018.03.093

14. Koc ER, Ersoy A, Ilhan A, Erken HA, Sahın S. Is rosuvastatin protective against on noise-induced oxidative stress in rat serum? Noise Health. 2015;17(74):11-6. doi: 10.4103/14631741.149565

15. Matović V, Buha A, Đukić-Ćosić D, Bulat Z. Insight into the oxidative stress induced by lead and/or cadmium in blood, liver and kidneys. Food Chem Toxicol. 2015;78:130-40. doi: 10.1016/j.fct.2015.02.011

16. Wybenga DR, Di Giorgio J, Pileggi VJ. Manual and automated methods for urea nitrogen measurement in whole serum. Clin Chem. 1971;17:891-5.

17. Junge W, Wilke B, Halabi A, Klein G. Determination of reference intervals for serum creatinine, creatinine and creatinine clearance with an enzymatic and a modified Jaffé method. Clin Chim Acta. 2004;344:137-48. doi: 10.1016/j. cccn.2004.02.007

18. Ellman GL. Tissue sulfhydryl groups. Arch Biochem Biophys. 1959;82:70-7.

19. Buege JA, Aust SD. Microsomal lipid peroxidation. Methods Enzymol. 1978; 52:302-10.

20. Helal G, Eid F, Taha NM. Effect of noise stress and/or sulpiride treatment on some physiological and histological parameters in female albino rats. Egypt J Hosp Med. 2011; 44:295-310.

21. Baldwin AL. Effects of noise on rodent physiology. Int J Comp Psychol. 2007;20:134-44.

22. Akinyemi AJ, Faboya OL, Paul AA, Olayide I, Faboya OA, Oluwasola TA. Nephroprotective Effect of Essential Oils from Ginger (Zingiber officinale) and Turmeric (Curcuma longa) Rhizomes against Cadmium-induced nephrotoxicity in rats. J Oleo Sci. 2018;67:1339-1345. doi: 10.5650/jos. ess18115.

23. Abdel-Moneim AM, Said KM. Acute effect of cadmium treatment on the kidney of rats: biochemical and ultrastructural studies. Pak J Biol Sci. 2007; 10:3497-506. doi: $\quad$ 10.3923/pjbs.2007.3497.3506.

24. Kim KS, Lim HJ, Lim JS, Son JY, Lee J, Lee BM, Chang SC, Kim HS. Curcumin ameliorates cadmium-induced nephrotoxicity in Sprague-Dawley rats. Food Chem Toxicol. 2018;114:34-40. doi: 10.1016/j.fct.2018.02.007.

25. Wongmekiat O, Peerapanyasut W, Kobroob A. Catechin supplementation prevents kidney damage in rats repeatedly exposed to cadmium through mitochondrial protection. Naunyn Schmiedebergs Arch Pharmacol. 2018;391:385-94. doi: 10.1007/s00210-018-1468-6.

26. Mohammed M. S, Gulrana K, Mohammad F A, Sohail H, Mohammad H A. S, Farah Islam and Fakhrul I. Cadmiuminduced nephrotoxicity via oxidative stress in male wistar rats and capsaicin protects its toxicity. Bull Env Pharmacol Life Sci. 2016;5:5-11.

27. Helal EG, Eid F, Taha NM. Protective effects of sulpiride treatment on kidney functions of female albino rats exposed to noise stress. Egyptian J Hospital Med. 2011;44:284-94.

28. Zymantiene J, Zelvyte R, Pampariene I, Aniuliene A, Juodziukyniene N, Kantautaite J, Oberauskas V. Effects of long-term construction noise on health of adult female Wistar rats. Pol J Vet Sci. 2017;20:155-165. doi: 10.1515/ pjvs-2017-0020.

29. Pal R, Nath R, Gill KD. Lipid peroxidation and antioxidant defense enzymes in various regions of adult rat brain after co-exposure to cadmium and ethanol. Pharmocol Toxicol. 1993;73:209-214. doi.10.1111/j.1600-0773.1993.tb01565.x.

30. Kershaw WC, Iga T, Klaassen CD. Ethanol decreased cadmium hepatotoxicity in rats: possible role of hepatic metallothionein induction. Toxicol Appl Pharmacol. 1990;106:448-55.

Copyright ( $\odot 2019$ The Author(s); Published by Nickan Research Institute. This is an open-access article distributed under the terms of the Creative Commons Attribution License (http://creativecommons.org/licenses/by/4.0), which permits unrestricted use, distribution, and reproduction in any medium, provided the original work is properly cited. 